\title{
The Contribution of Professional Youth Work to the Personal Development and Social Participation of Socially Vulnerable Youngsters: A Dutch Longitudinal Cohort Study
}

\author{
Jolanda Sonneveld ${ }^{1,4}$ (D) Judith Metz ${ }^{1} \cdot$ Willeke Manders $^{1} \cdot$ René Schalk $^{3,4} \cdot$ Tine Van Regenmortel $^{2,4}$
}

Accepted: 24 April 2021 / Published online: 2 May 2021

(c) The Author(s) 2021

\begin{abstract}
This article focuses on how length of participation in professional youth work is associated with five outcome variables: prosocial skills, self-mastery, social network, civic participation (volunteering and organizing activities) and finding support from social care services. The study was designed as a longitudinal cohort study of four waves during a 16-month period, gathering the data of 1597 youngsters aged 10-24 who participated in Dutch professional youth work. The results show that, on average, youngsters who participated longer in youth work scored significantly higher on the outcome variables. Respondents did not show individual improvements on outcome variables over the period, but the results demonstrate a cautious positive trend over time in volunteering. Referring youngsters (33\%) by youth workers to care services could prevent an exacerbation of existing problems. The results provide knowledge that legitimizes the role of professional youth workers and which can be used by them to improve the support of socially vulnerable youngsters in their personal development and social participation.
\end{abstract}

Keywords Socially vulnerable youth · Professional youth work · Multi-methodic approach · Longitudinal cohort study Development $\cdot$ Length of participation

Within Western welfare states, youth policy makers and social work practice are paying increasing attention to how professional youth work contributes to the personal development and social participation of youngsters, preventing social and (mental) health problems (Fish, 2014) and reducing the growing number of young people in social care institutions (CBS, 2020). From a theoretical focus on positive youth development, there is a growing belief that strengthening support for personal development, reinforcement

Jolanda Sonneveld

j.j.j.sonneveld@hva.nl

1 Centre for Applied Research in Social Work and Law, Amsterdam University of Applied Sciences, 1091 GH Amsterdam, The Netherlands

2 Faculty of Social Sciences - HIVA, University of Leuven, Leuven, Belgium

3 Economic and Management Sciences, North-West University, Potchefstroom, South Africa

4 Tilburg School of Social and Behavioral Sciences, Tranzo, Tilburg University, Tilburg, The Netherlands of social networks and enhancement of civic participation may be reducing risks and problems and preventing the need for social care in young people's lives (Catalano et al., 2004). There is also a lack of large-scale empirical research on the contribution of professional youth work to the personal development and social participation of youngsters (McGregor, 2015). This study intended to address this knowledge gap by focusing on whether participation in professional youth work actually contributes to the personal development and greater social participation of youngsters.

Professional youth work in the Netherlands is a relatively small profession (1500 paid workers), undertaken by public welfare organizations and usually funded by local governments. Professional youth workers demonstrably master relevant knowledge, skills, and attitudes, which are obtained through a combination of formal education, peer learning and experience working with young people (Metz, 2017). As in most other European countries, there is not one particular training program for youth workers in the Netherlands; rather, broader vocational education or a Bachelor's degree (in social work) which includes the field of youth work can be followed (Dunne et al., 2014). In performing youth work 
activities, professional youth workers often also work with volunteers. Youth work is positioned in the leisure time of youngsters and plays a preventive role in a wide range of informal contexts, such as youth clubs, sports facilities, online, or on the streets (Baillergeau \& Hoijtink, 2010). Compared to project-based after-school youth development programs in the United States (Larson et al., 2019), professional youth work in Western welfare states also offers "unstructured" activities in settings where young people can chill out.

Professional youth workers engage primarily with youngsters between the ages of 10 and 24 who are growing up in socially vulnerable positions (Dunne et al., 2014; Metz, 2017). The term "social vulnerability" refers to the structurally vulnerable position of specific individuals or groups in society (e.g., those in deprived neighborhoods), who may have negative experiences with social institutions which often leads to distorted relationships and social disconnectedness (Vettenburg, 1998). Youngsters who grow up in socially vulnerable positions face challenges and developmental burdens in addition to dealing with the complexity of the developmental challenges generally faced by youngsters in the twenty-first century (Larson, 2011). Socially vulnerable youth often experience a lack of encouragement and support from people in their social environment (Abdallah, 2017); they grow up in low-income families and have to deal with poverty (Doherty \& De St. Croix, 2019) and/or have social and/or mental health problems, such as insufficient prosocial skills, depressive feelings, or stress-related illnesses that hinder their opportunity to fully participate in society. The risk of developing problems in their transition to adulthood is significantly higher for youngsters who accumulate negative experiences in their social environment (Vettenburg, 1998), and they are more likely to be in need of relatively expensive, possibly specialized social care services (Henderson et al., 2016). Because of their socially vulnerable position in society, professional youth workers support these youngsters in the process of becoming an independent adult. Within this group targeted by professional youth work, a division is made between youngsters who are doing well, youngsters with minor or initial problems, and youngsters with severe and multiple disadvantages (Sonneveld et al., 2020).

Professional youth work is based on voluntary participation, which emphasizes that the youngsters choose whether, how much, and for how long they want to be involved (Jeffs \& Smith, 1999). Basically, this voluntary involvement is the most common and defining characteristic of professional youth work, along with the fact that it focuses on the experiences, needs, and interests of each youngster (Batsleer, 2008; McGregor, 2015).

Youth workers engage with youngsters in a broad age group (10-24) because they build lasting and meaningful relationships with them throughout their adolescence. Youngsters often participate in youth work for years because it offers them a safe and familiar environment in their leisure time (Taru, 2010). Most young people involved start when they are about 10 or 12 years old and leave when they are about 18. Some participate up to the age of 24 (Sonneveld $\&$ Metz, 2019) because they want to volunteer for youth work or need continued support in their struggle with severe and multiple disadvantages. Older youth who face problems often receive additional specialized care from social care services. For many, the youth work environment is a "home away from home," a space of safety and escape from the conflicts or pressures of everyday life (school or home), where they achieve a sense of belonging (Fyfe et al., 2018; Nolas, 2014).

Youth workers begin with the experiences, needs and interests of the youngsters (Batsleer, 2008). With this lifeworld as a starting point, youth workers use an open approach (Metz, 2016), which does not follow a pre-planned and time-limited specific intervention but methodical actions that are fluid and responsive to the specific needs and interests of the youngsters and the changing social and political context in which they occur (Doherty \& De St. Croix, 2019; Ord, 2014).

Taking this open approach, Dutch professionals apply a combination of four commonly used methods within youth work: detached youth work, social group work, individual guidance, and information and advice services (Metz, 2020). Detached youth work establishes contact with youngsters and provides services in young people's living environment (Milburn et al., 2000). Social group work recognizes the significant influence of social peer interactions and group processes for the development of important life skills required to become an independent adult, fostering peer sociability and support, and the enhancement of social participation (Rumping et al., 2017). Through the provision of information and advice services and sometimes more prolonged individual guidance, youth workers offer accessible support in resolving (initial) problems concerning school, work or relationships; for example, enhancing the youngsters' ability to make informed decisions about their lives (Bradford, 2000; Koops et al., 2014; Manders \& Metz, 2017). The application of one or more of these methods depends on the specific needs of each individual and their current situation and is known as a multi-methodic approach (Sonneveld et al., 2020).

The voluntary, open-ended and process-oriented character of youth work implies that its outcomes are unpredictable (Ord, 2014; Metz, 2016; De St. Croix, 2018), and identifies youth work as a particularly challenging context for empirical research (Doherty \& De St. Croix, 2019; Ord, 2014). Despite this challenge, our knowledge base on the prevention efforts of professional youth work has expanded over 
the past five years. A qualitative research synthesis (Sonneveld et al., under review) of six European studies (Fyfe et al., 2018; Koops et al., , 2013, 2014; Ord et al., 2018; Rumping et al., 2017; Schaap et al., 2017) revealed that a multi-methodic youth work approach could contribute to the following outcomes: strengthening social skills and self-mastery of youngsters, reinforcement of their social network, enhancement of their civic participation, and finding additional support from relevant social or health care institutions. These outcome variables are in line with Dutch youth policy (2015) (Bosscher, 2014) in which it is assumed that these variables may help youngsters thrive and avoid personal and social problems, which may have longer term positive social returns.

The first outcome variable, prosocial skills, is essential for young people to function well in society, to promote harmonious relationships and prevent behavioral problems causing conflicts with others (Bergin et al., 2003). The presence of rules and structure during group-based youth work activities and feedback during individual guidance help youngsters to understand which prosocial skills are necessary for social integration into society (Sonneveld et al., 2020). Small snippets of research evidence suggest that professional youth work contributes to the development of prosocial skills, such as having respect for others, and improvements in relationships with adults, including teachers, youth work staff and family (Dickson et al., 2013; Fyfe et al., 2018; Ord et al., 2018; Rumping et al., 2017).

The second outcome variable is self-mastery, or the extent to which an individual believes that he or she has control over important life circumstances and stressful conditions (Pearlin \& Schooler, 1978). Adolescence is a crucial phase for the development of self-mastery (Conger et al., 2009) as an important component of psychological empowerment (Zimmerman, 1995). Youth workers aim to boost youngsters' self-mastery by enhancing their ability to make informed decisions about their lives, supporting them in harnessing it effectively (Bradford, 2000), learning to set goals (Fish, 2014) and taking responsibility for achieving them (Dworkin et al., 2003). There are indications that professional youth work could increase self-mastery of youngsters (Ord et al., 2018; Boomkens et al., 2019b).

A third outcome that has been attributed to participation in youth work is reinforcement of the social network. Social networks consist of people (family, peers, neighbors) who are of varying degrees of importance to the youngsters. This not only concerns the number of people within the social network, but also the feeling of belonging and feeling familiar with other people (Bartelink \& Verheijden, 2015). Youngsters who can count on informal social support (a listening ear, appreciation, advice, belonging) from their social network function better, experience fewer problems (Cavanaugh \& Buehler, 2015) and are less likely to need social care (Metz, 2020). Previous research has shown that participation in professional youth work activities enables youngsters to build positive relationships with peers and receive support from peers and adults (Dunne et al., 2014; Fyfe et al., 2018; Ord et al., 2018).

Fourth, youth work aims to contribute to the enhancement of civic participation, such as volunteering and organizing activities in the neighborhood. Civic participation offers youngsters opportunities to develop skills, understand other perspectives/cultures, enter into new social relationships and spend their time constructively. In this way, civic participation has a positive effect on the wellbeing of young people (Ince et al., 2018). Previous research suggests that participation in group-based activities and volunteering in youth work contexts contributes to the development of youngsters into responsible, active citizens, who take on leadership opportunities both within the youth work environment (as role models) and elsewhere (Fyfe et al., 2018; Rumping et al., 2017).

Finally, finding (specialized) care. Characteristic for the group targeted by youth workers is that social support is not always present and youngsters with sometimes severe disadvantages are often not receptive to the idea of assistance from care professionals because they have difficulties trusting them due to bad past experiences (Boomkens et al., 2019a). Previous research suggests that individual guidance and information and advice services help connect youngsters with social care institutions and are essential in anticipating needs and sign-posting these additional services (Fyfe et al., 2018; Koops et al., 2014; Manders \& Metz, 2017).

\section{Focus of the Current Study}

Previous research gives good reason to expect positive effects of a multi-methodic youth work approach on the five outcome variables mentioned. However, the actual contribution of such an approach has not yet been investigated through large-scale longitudinal empirical research. Previous studies are mainly small-scale qualitative studies (Dunne et al., 2014; Mc Gregor, 2015). In addition, "length of participation" in youth work has not yet been investigated as a variable related to the positive development of youngsters, although there are cautionary indications that participation of three years or longer may positively influence the development of youngsters (Taru, 2010). This study therefore investigates whether participation in professional youth work settings with a multi-methodic approach contributes to five variables: improvements in prosocial skills; improvements in self-mastery; reinforcement of the social network; enhancement of civic participation; and finding (specialized) care when needed. We also consider the length of participation to investigate whether youngsters who are engaged 
longer in youth work activities score higher on outcome variables than youngsters who are engaged for a shorter period.

\section{Method}

\section{Design}

An accelerated longitudinal multiple cohort design was used to answer the research questions. This design allowed us to collect data about youth work participants at four time points (between September 2017 and December 2018, at intervals of 3-4 months) and to compare the development of three cohort groups of youngsters who vary in the length of participation in youth work settings at baseline: participation for 0-6 months; participation for 7 months-2 years; and participation for 3 years or longer. We considered the 0-6 months participation cohort group as a reference group in this study. By following the other two cohort groups at the same time and comparing them to the first, we could examine the influence of participation in youth work settings. Examining and comparing several cohorts at the same time provides the opportunity to gain insight into the development of participants over a relatively short time (Galbraith et al., 2017). This is important to meet the urgent needs of practice and for policy makers to gain insight into the preventive value of youth work.

The study was conducted in close collaboration with 11 Dutch professional youth work providers from urban areas in the middle, south and east parts of the Netherlands. All of the providers are public welfare organizations funded by local government, and all invest in the professionalization of youth work practice. All of them apply a multi-methodic approach in reaching out to youngsters (boys and girls) in a broad age group (10-24). One organization mainly focuses on young people with severe and multiple disadvantages, while other organizations focus on all three subgroups targeted. The organizations offer a good reflection of professional youth work in the Netherlands and actively approached the research group to conduct in practice-based research that would contribute to the further professionalization of youth work. In addition to granting access to their practice for data collection, the collaboration involved participation of youth workers in a Youth Worker Lab $(\mathrm{N}=11)$ and participation of diverse adolescents in a Youth Panel $(\mathrm{N}=14)$.

The participation with the Youth Worker Lab and Youth Panel ensured the research instruments and the process of data collection were appropriate to youth work practice from the perspective of both youth workers and youngsters. During two meetings, these two groups were consulted to support the development of the questionnaire and to discuss how data should be collected. After analyzing the data, youth workers who participated in the Youth Worker Lab were consulted for reflection on the results, which contributed to ensuring validity.

\section{Participants}

For sample selection, a short questionnaire was first distributed to the 11 organizations involved to gain insight into the population of youngsters in each organization (age groups, level of problems) and their participation in youth work settings (length of participation, combination of methods). This information allowed a profile of the population to be drawn up for each organization, with the 11 profiles used to compose a representative sample of adolescents from different age groups, with different levels of problems, a different length of participation and who received different methods. The youngsters recruited to the study fulfilled four criteria: (1) participation in one of the 11 youth work organizations; (2) at least 10 years old and younger than 25; (3) sufficient command of Dutch and (4) familiar with at least one of the four methods offered by youth work. Thirteen youngsters were excluded because they did not meet the inclusion criteria or withheld approval. Another 35 youngsters were excluded because they did not fully complete the first questionnaire. In total, 1597 youngsters were included in the analysis (Fig. 1). The number of youngsters from each youth work organization varied between 66 and $227(\mathrm{M}=145$, $\mathrm{SD}=45.8$ ). Participants were approached four times for self-reporting: T1, Sept-Dec 2017, N=1,597; T2, Jan-April 2018, N=981; T3, May-Aug 2018, N=626; T4, Sept-Dec 2018, $\mathrm{N}=595$. Of the total participants, $19.8 \%(\mathrm{~N}=316)$ participated in all four waves of data collection, $26.4 \%$ $(\mathrm{N}=421)$ participated in three waves, $24.9 \%(\mathrm{~N}=398)$ in two waves and $28.9 \%(\mathrm{~N}=462)$ dropped out after the first wave. The response rates are shown in Fig. 1. Non-completion was defined as completing none, one or two of the three post-measurements. Reasons for non-completion at follow up were (temporary) positive outflow, refusal, (temporary) loss of contact, and organizational reasons. Table 1 shows the data collected on non-response for Waves 2-4.

We examined characteristics of non-completers with a T-test and Chi square. Youngsters who missed questionnaires were more often boys $(69.2 \%)$ compared to the completers $(50.9 \%)\left(x^{2}=37.6, p \leq 0.001\right)$, and were older in age compared to the completers (16.6 and 16.0 years, respectively, $\mathrm{t}=2.69, p=0.007)$. Non-completers were more often youngsters who participated 0-6 months $(85.6 \%)$ or 7 months-2 years $(80.4 \%)$ in youth work, compared to youngsters who had participated 3 years or longer $(76.2 \%)$ $\left(x^{2}=14.68, p=0.001\right)$. Table 2 provides the descriptive statistics for the participants that were included in the analysis. Most youngsters in our sample were aged between 14 and 17 years $(40 \%)$ and the mean age was 16.5 years $(\mathrm{SD}=3.60)$. 
Fig. 1 Participant flowchart

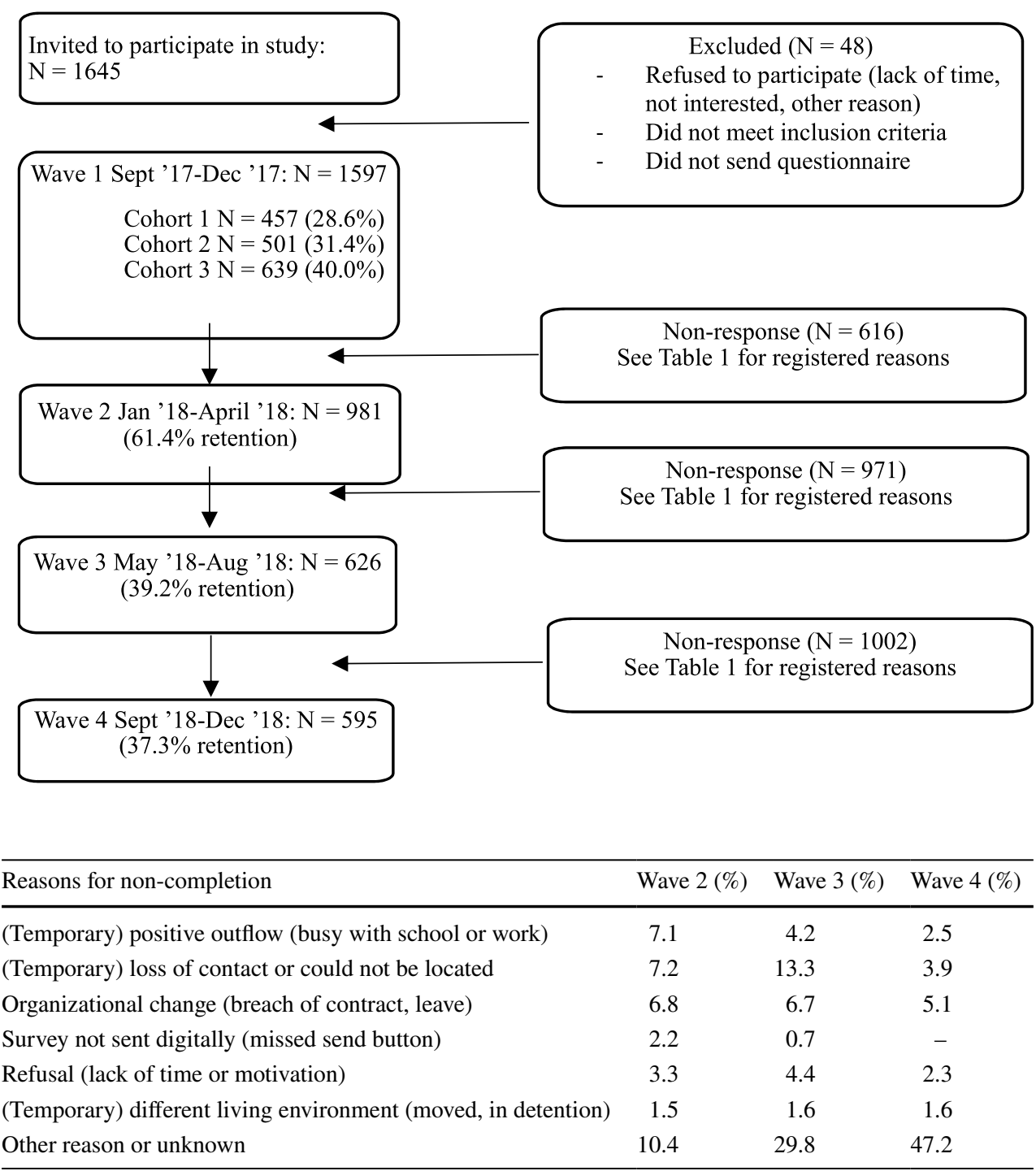

Table 1 Reasons for noncompletion

\begin{tabular}{lccc}
\hline Reasons for non-completion & Wave 2(\%) & Wave 3 (\%) & Wave 4 (\%) \\
\hline (Temporary) positive outflow (busy with school or work) & 7.1 & 4.2 & 2.5 \\
(Temporary) loss of contact or could not be located & 7.2 & 13.3 & 3.9 \\
Organizational change (breach of contract, leave) & 6.8 & 6.7 & 5.1 \\
Survey not sent digitally (missed send button) & 2.2 & 0.7 & \multicolumn{2}{c}{-} \\
Refusal (lack of time or motivation) & 3.3 & 4.4 & 2.3 \\
(Temporary) different living environment (moved, in detention) & 1.5 & 1.6 & 1.6 \\
Other reason or unknown & 10.4 & 29.8 & 47.2 \\
\hline
\end{tabular}

There were more males $(65.6 \%)$ than females $(34.4 \%)$. It is known that girls are underrepresented in youth work activities (Boomkens et al., 2019b), with Gemmeke et al. (2011) noting that only $10-30 \%$ of the youngsters in youth work are girls. In relation to cultural background, $21 \%$ of the youngsters reported a native Dutch background and $31 \%$ reported a Dutch bi-cultural background (e.g., Dutch and Moroccan). Of those attending school $(79.3 \%, \mathrm{~N}=1242), 14.6 \%$ were in primary school, $67.3 \%$ vocational education and $18.0 \%$ higher education.

A sample of 322 youngsters per cohort is sufficient to test the differences between three cohorts based on 0.80 power and a small effect size (Cohen, 1992). Figure 1 shows we meet these assumptions to test differences between the three cohorts regarding length of participation. Table 3 shows the number of respondents for methods of youth work being used.

\section{Procedures}

For the data collection, we collaborated with all 11 organizations. At least one manager $(\mathrm{N}=12)$ and ten youth workers $(\mathrm{N}=150)$ participated from each organization. Two researchers (including author one) gave instructions for data collection verbally during training, which included an introduction to the study; instructions on adhering to the research protocol; acquiring respondents; inclusion criteria; informed consent procedure; procedure for digital data collection; and guaranteeing the reliability of the data. Supplementary youth workers received a field guide with instructions. After completing the training, the 150 youth workers were asked to select at least ten youngsters from their own practice to participate in the study. The researchers and trained youth workers planned how they would reach a diverse group of young people, taking into account differences in: (1) gender (boys and girls); (2) age (10-24); (3) the extent of personal or 
Table 2 Demographic variables of youth at Wave $1(\mathrm{~N}=1597)$

\begin{tabular}{ll}
\hline Demographics & N $(\%)$ \\
\hline Age & $\begin{array}{c}\text { Mean } 16.5 \\
\text { SD }=3.60 \\
(\text { range 10-24) }\end{array}$ \\
Gender & $1048(65.6 \%)$ \\
Male & $549(34.4 \%)$ \\
Female & \\
Cultural background & $335(21.0 \%)$ \\
Only Dutch & $490(30.7 \%)$ \\
Combination Dutch and other & $772(48.3 \%)$ \\
Not Dutch & \\
Activity during the day & $1267(79.3 \%)$ \\
School/education program & $184(11.5 \%)$ \\
Work & $42(2.6 \%)$ \\
Care responsibilities or volunteering & $90(5.6 \%)$ \\
No activity during the day & \\
Educational level (N=1242) & $181(14.6 \%)$ \\
Primary education & $836(67.3 \%)$ \\
Vocational education & $225(18.0 \%)$ \\
Higher education &
\end{tabular}

social problems (doing well; minor/initial problems; severe and multiple disadvantage); and (4) length of participation (0-6 months; 7 months -2 years; 3 years or longer). Youth workers verbally informed youngsters (and their primary caregiver, if they were younger than 16) about the study and asked them whether they were interested in participating. If they were interested, the youth workers gave them a letter provided by the researchers. Participants were made aware of their rights (such as voluntary participation, right to withdraw, confidentiality and anonymity). If youngsters were younger than 12 , the youth worker also verbally contacted the caregiver(s) to obtain verbal consent in addition to the letter. Before the first questionnaire, digital consent was also required to ensure informed consent. The youngsters completed the questionnaires online in private using tablets. They were able to consult another person if they had any questions, preferably a person other than the youth worker, to reduce socially desirable answers. The research team maintained close contact with the youth workers to ensure greater levels of response, and the team monitored the process and missing data points. Data cleaning was done as soon as the data were collected. The study protocol was approved by the managements of the 11 participating organizations and youth workers from the Youth Work Lab. Data collection was carried out in accordance with the Netherlands Code of Conduct for Research Integrity (2018).

\section{Instruments}

We collaborated with the Youth Worker Lab and the Youth Panel to develop an appropriate questionnaire that was suitable for a broad age group (10-24) and for young people with a lower language level. Based on feedback from a pilot, we concluded that the first version of the questionnaire was too long and some of its concepts too complicated, which could potentially adversely affect the existing relationships between youth workers and youngsters (De St. Croix, 2018), and major drop-out from repeated measurements. To combat respondent fatigue, we shortened and simplified the questionnaire through scale adaptation (Heggestad et al., 2019) on some validated scales. Furthermore, we designed items and scales ourselves based on the existing literature if there were no suitable instruments available.

\section{Demographic Variables and Participation in Youth Work}

Demographic information included age, gender, cultural background, activity during the day and educational level. One question, "How long have you had contact with youth workers?," was used in Wave 1 to proxy the length of participation in youth work settings. In addition, we asked youngsters about their level of intensity of participation at each time point.

\section{Multi-Methodic Youth Work}

The multi-methodic approach was measured at each time point with four items designed for this study based on the literature (Koops et al., 2013, 2014; Manders \& Metz, 2017; Rumping et al., 2017). Youth self-report on participating in social group work, receiving individual guidance and/ or information and advice services was assessed with three single dichotomy questions (yes or no). For example, the item, "I participated in group-based youth work activities
Table 3 Youth work methods in cohort groups

\begin{tabular}{lclll}
\hline Methods & Total N (\% of total) & $\begin{array}{l}\text { 0-6 months } \\
\mathrm{N} \%\end{array}$ & $\begin{array}{l}\text { 7 months-2 years } \\
\mathrm{N} \%\end{array}$ & $\begin{array}{l}3 \text { years or longer } \\
\mathrm{N} \%\end{array}$ \\
\hline Group work & $1067(67 \%)$ & $264(24.7 \%)$ & $349(32.7 \%)$ & $454(42.5 \%)$ \\
Individual guidance & $786(49 \%)$ & $177(22.5 \%)$ & $266(33.8 \%)$ & $343(43.6 \%)$ \\
Information and advice & $994(62 \%)$ & $231(23.2 \%)$ & $331(33.3 \%)$ & $432(43.5 \%)$ \\
Detached youth work & $1127(71 \%)$ & $294(26.1 \%)$ & $361(32.0 \%)$ & $472(41.9 \%)$ \\
\hline
\end{tabular}


(e.g., cooking, soccer or space to hang out) during the past 3 months," was used to assess whether respondents had been involved in social group work. To assess detached youth work, the respondents self-reported where they had engaged with the youth worker during the last 3 months. Respondents could indicate multiple answers (e.g., on the street, at home, snack bars or cafés).

\section{Outcome Measures}

Prosocial skills were assessed at each time point by one of the five subscales of the Dutch version of the self-report Strengths and Difficulties Questionnaire (SDQ) (Widenfelt et al., 2003). The SDQ self-report was developed to assess the psychosocial adjustment of adolescents (aged 11-17). The prosocial behavior scale consists of five items concerning both strengths and difficulties; for example, "I often offer to help others (parents, teachers, children)." To keep the scale level the same for all outcome measures, we adjusted the response scale from the original three-point Likert scale to a five-point option ranging from "strongly disagree" to "strongly agree." Higher scores indicated higher prosocial behavior. The internal consistency of this subscale was computed as $\alpha=0.77$ at baseline in the sample.

We adapted the Dutch version (Kempen, 1992) of the Pearlin Mastery Scale (PMS) (Pearlin \& Schooler, 1978) to measure the extent to which youngster's self-mastery improved. The PMS is a widely used measure, including among adolescents, which assesses "the extent to which people see themselves as being in control of the forces that importantly affect their lives" (Pearlin et al., 1981, p. 340). Each item (e.g., "I have little control over things that happen to me") is answered on a five-point scale, with options ranging from "strongly agree" to "strongly disagree." Higher scores indicated higher mastery. We excluded item 2 ("Sometimes I feel that I'm being pushed around in life") because the pilot showed that this item was misinterpreted by youngsters. In the current study, the alpha coefficient indicated reliability $(\alpha=0.78)$ at baseline in the sample.

The youngsters' social network was measured with a 6-item instrument designed for this study. Research by Asselt-Goverts (2016) about social network analysis for people with an intellectual disability inspired us to design the instrument. The items used in this study were formulated in simple language and therefore suitable for our respondents, who generally had a lower language level.

At each time point, the six items, scored on a five-point scale, assessed youth self-reported number of contacts with family and friends (ranging from " $0-5$ " to " 30 or more"), whether young people received support from family and friends (ranging from "never" to "always") and whether they were satisfied with the support received (ranging from "very dissatisfied" to "very satisfied"). Higher scores indicated a more extensive social network. Cronbach's alpha was computed as $\alpha=0.71$ at baseline in the sample.

Youth self-report of civic participation was assessed with two items to provide insight into the quantity of activities in social contexts (Item 1: "How often have you volunteered?"; Item 2: "How often have you organized an activity in your neighborhood?") During each measurement we asked about the past 3 months. Results were analyzed at item level.

We assessed finding (specialized) care at each time point by asking the youngsters whether they found care services through youth workers during the last 3 months. They could choose different answer categories on a list, such as a social care institution for debt or addiction, a doctor or the Social District Team (Koops et al., 2014).

\section{Statistical Analyses}

Descriptive statistics were used to illustrate the demographic and other characteristics of the sample and to provide a useful outline for the outcome variable of finding (specialized) care. Respondents were split into three age groups (10-14 years, 15-19 years, 20-24 years).

As a necessary condition for analyzing data from a longitudinal cohort design (Duncan et al., 1996), we began by using Chi-square and univariate ANOVA tests to determine whether the different cohorts were comparable with respect to the attributes being measured. Comparing demographics between the three groups of participants, we found no significant differences based on gender $\left(x^{2}=4.94^{\text {n.s. }}, p=0.085\right)$. However, significant differences were found between groups on the variables of age $(F=17.43, p<0.001)$, cultural background $\left.x^{2}=15.32, p=0.02\right)$, and intensity of participation in youth work $(F=6.99, p=001)$. Furthermore, younger adolescents and youngsters with a native Dutch background were less represented in Cohort 3 (participation 3 years or longer), while youngsters in Cohort 1 (0-6 months participation) participated less intensively in youth work settings compared to youngsters in the other two cohort groups. We, therefore, controlled for any confounding on these three variables in our analysis.

Because observations were made repeatedly over four time points, we used Linear Mixed Models (LMM) to answer the research questions. Multiple imputation of missing values was not necessary because LMM includes participants in the analysis who have not completed all measurements (dependent variables) (Twisk et al., 2013). LMM provides an understanding of both the mean levels of the outcome variables (average over time) and the changes in mean levels over the four time points. A two-level (repeated measures were clustered within youngsters) linear mixed model was constructed with restricted maximum likelihood estimation. The variance at organizational level was also checked, but did not explain differences, and therefore it was not included 
in the models. The model intercept was specified as random across individuals, while other parameters were specified as fixed. We used unstructured covariance.

First, we explored the mean differences between cohorts over the four time points. These mean differences indicate how the factor of "length of participation" influences the scores on outcome variables. The between-group effect size was calculated according to Cohen's d. Second, we modeled time as a categorical variable to assess improvements of the three cohorts on outcome variables over a period of 16 months. Undertaking an analysis for each cohort group, it was possible to observe in detail how the different groups developed over time. We did not calculate effect sizes for these results because some scholars discourage reporting effect sizes for within-group changes (pre-post within one group); for example, because pre- and post-test results tend to be dependent (Cuijpers et al., 2017). All analyses were conducted using SPSS 24. Statistical significance was assessed at the 0.05 level.

\section{Results}

\section{Descriptive Statistics}

Of the youngsters, $33 \%(\mathrm{~N}=520)$ reported at one or more time points that they found support or help from a social care organization through their youth worker. This could be a doctor, a professional from a Social District Team or a social care institution. These youngsters who had found (specialized) care were then examined in terms of the three cohort groups: $29.0 \%$ had been engaged with a youth worker at Wave 1 for $0-6$ months; $32.5 \%$ for 7 months to 2 years; and $38.5 \%$ for 3 years or longer.

\section{Differences Between Groups}

Table 4 reports how youngsters who had participated in youth work for 0-6 months at baseline (reference group) compare with their peers who had participated longer (7 months to 2 years, or 3 years or longer) on levels of prosocial skills, self-mastery, social network and civic participation (volunteering and organizing activities). Statistically significant associations between length of participation and outcome measures were found averaged over time. Longer participation in youth work, led to higher scores on the outcome variables. Youngsters who received support for 7 months or longer had significantly higher scores for social network $(\mathrm{M}=3.53$, CI 3.52, 3.62, $p<0.001)$, self-mastery $(\mathrm{M}=3.52$, CI $3.47,3.57, p=0.048)$ and organizing activities $(\mathrm{M}=1.98, \mathrm{CI} 1.88,2.08, p<0.001)$
Table 4 Results of Linear Mixed Models Analyses of length of participation on outcome variables

\begin{tabular}{|c|c|c|c|c|}
\hline Fixed effects & Mean & SE & $95 \% \mathrm{CI}$ & $\begin{array}{l}\text { Between-group } \\
\text { effect sizes (d) }\end{array}$ \\
\hline \multicolumn{5}{|l|}{ Prosocial skills } \\
\hline Overall mean & 4.12 & 0.01 & {$[4.10,4.14]$} & \\
\hline Cohort 1 & 4.06 & 0.02 & {$[4.03,4.12]$} & \\
\hline Cohort 2 & $4.11^{\mathrm{ns}}$ & 0.03 & {$[4.07,4.16]$} & 0.08 \\
\hline Cohort 3 & $4.15^{*}(0.021)$ & 0.03 & {$[4.11,4.19]$} & 0.14 \\
\hline \multicolumn{5}{|l|}{ Self-mastery } \\
\hline Overall mean & 3.54 & 0.01 & {$[3.51,3.57]$} & \\
\hline Cohort 1 & 3.50 & 0.02 & {$[3.45,3.55]$} & \\
\hline Cohort 2 & $3.52 *(0.048)$ & 0.04 & {$[3.47,3.57]$} & 0.03 \\
\hline Cohort 3 & $3.59 *(0.012)$ & 0.03 & {$[3.54,3.63]$} & 0.13 \\
\hline \multicolumn{5}{|l|}{ Social network } \\
\hline Overall mean & 3.50 & 0.18 & {$[3.46,3.53]$} & \\
\hline Cohort 1 & 3.36 & 0.03 & {$[3.30,3.43]$} & \\
\hline Cohort 2 & $\begin{array}{l}3.53 * * * \\
(<0.001)\end{array}$ & 0.05 & {$[3.47,3.59]$} & 0.21 \\
\hline Cohort 3 & $\begin{array}{l}3.57 * * * \\
\quad(<.001)\end{array}$ & 0.04 & {$[3.52,3.62]$} & 0.26 \\
\hline \multicolumn{5}{|l|}{ Volunteering } \\
\hline Overall mean & 2.07 & 0.03 & {$[2.00,2.13]$} & \\
\hline Cohort 1 & 1.83 & 0.06 & {$[1.71,1.96]$} & \\
\hline Cohort 2 & $1.94^{\mathrm{ns}}$ & 0.09 & {$[1.82,2.06]$} & 0.07 \\
\hline Cohort 3 & $\begin{array}{l}2.33 * * * \\
\quad(<0.001)\end{array}$ & 0.08 & {$[2.22,2.43]$} & 0.31 \\
\hline \multicolumn{5}{|c|}{ Organizing activities } \\
\hline Overall mean & 1.91 & 0.03 & {$[1.85,1.96]$} & \\
\hline Cohort 1 & 1.73 & 0.05 & {$[1.63,1.84]$} & \\
\hline Cohort 2 & $\begin{array}{l}1.98 * * * \\
(<0.001)\end{array}$ & 0.07 & {$[1.88,2.08]$} & 0.18 \\
\hline Cohort 3 & $\begin{array}{l}1.98 * * * \\
(<0.001)\end{array}$ & 0.07 & {$[1.89,2.06]$} & 0.18 \\
\hline
\end{tabular}

All models are controlled for age, cultural background and intensity of participation

$\mathrm{d}=\left(\mathrm{m}_{2}-\mathrm{m}_{1} / \mathrm{SD}_{\text {pooled }}\right)$

$* * *$ Significant at $<0.001 ; \quad * *$ significant at $<0.01 ; \quad *$ significant at $<0.05 ; n s$ not significant

compared to youth who participated for a shorter period. Youngsters who participated three years or longer had significantly higher scores for prosocial skills $(\mathrm{M}=4.15$, CI $4.11,4.19, p=0.021)$ and volunteering $(\mathrm{M}=2.33, \mathrm{CI}$ $2.22,2.43, p<0.001)$ compared to youngsters who had participated for less than three years. Controlling for age, cultural background and "intensity of participation" did not significantly alter the findings. The results show effect sizes of 0.21 and 0.26 for the outcome variable "social network" and 0.31 for the outcome variable "volunteering" between Cohorts 1 and 3. The effect size remained below 0.20 for the other outcome variables. 


\section{Development Over Time}

Table 5 presents the means of the outcome variables at each time point for each cohort group. It is noteworthy that the youngsters in all groups indicated at time point 1 that they had prosocial skills, self-mastery and support of their social network. The results show that youngsters in Cohort 1 did not significantly improve over the 16 months. Compared to the first wave, there is a small decrease in outcome variables on prosocial skills $(\beta=-0.13, \rho 0.015)$ and social network $(\beta=-0.13, \rho 0.033)$ at Wave 4 . While the youngsters in this cohort improved in volunteering, this change was not significant. In the other two cohort groups, there were also no significant improvements observed on the outcome variables of prosocial skills, self-mastery, social network and organizing activities. Only in Cohort 3 was there a significant improvement in volunteering at Wave 4 ( $\beta=0.24, \rho 0.011)$, compared to the first wave. Overall, with the exception of volunteering, no significant improvement was observed on outcome measures in a measurement period of 16 months.

\section{Discussion}

This longitudinal study examined whether socially vulnerable youngsters (aged 10-24) who partake in Dutch professional youth work with a multi-methodic approach develop prosocial skills and self-mastery, reinforce their social network, enhance their civic participation (volunteering and organizing activities) and find (specialized) care if needed. We compared three groups of youngsters who differed from each other on the variable "length of participation." Descriptive statistics showed that $33 \%$ of the youngsters divided over the three groups gained access to (specialized) care services with the support of youth workers. This result confirms that youth work meets youngsters' need for additional support/care when they are faced with developmental issues or problems, which could prevent the accumulation of problems and more expensive and long-term care (Coulston, 2010). It is important to note that not all young people who participate in youth work need additional support or help. However, this finding shows that youth workers are able to encourage youngsters with initial or severe problems to obtain help and to connect youngsters to appropriate social care services.

The results of the linear mixed models analyses were mixed. The mean differences over time between cohort groups indicated a statistically significant association between length of participation and levels of the outcome variables. A difference for 7 months participation was observed for self-mastery, social network and organizing activities and for 3 years participation on prosocial skills and volunteering. We found a practical impact on volunteering $(d=0.31)$ and social network $(d=0.26)$. Given the fact that youth work is a preventive service, in which a large group of young people can participate on a voluntary basis, small
Table 5 Development over time of the outcome variables with time treated as a categorical variable

\begin{tabular}{|c|c|c|c|c|}
\hline Fixed & Mean: Wave 1 & Mean: Wave 2 & Mean: Wave 3 & Mean: Wave 4 \\
\hline \multicolumn{5}{|l|}{ Cohort $1(\mathrm{~N}=457)$} \\
\hline Prosocial skills & $4.11[4.05,4.17]$ & $4.07[4.00,4.14]$ & $4.04[3.96,4.13]$ & $3.98 *[3.89,4.08]$ \\
\hline Self-mastery & $3.52[3.46,3.58]$ & $3.48[3.41,3.56]$ & $3.49[3.39,3.58]$ & $3.48[3.38,3.59]$ \\
\hline Social network & $3.40[3.33,3.48]$ & $3.35[3.26,3.42]$ & $3.32[3.21,3.43]$ & $3.27 *[3.15,3.39]$ \\
\hline Volunteering & $1.78[1.65,1.91]$ & $1.90[1.74,2.06]$ & $1.81[1.62,2.01]$ & $1.97[1.75,2.19]$ \\
\hline Organizing activities & $1.75[1.63,1.87]$ & $1.69[1.54,1.84]$ & $1.76[1.57,1.94]$ & $1.70[1.49,1.91]$ \\
\hline \multicolumn{5}{|l|}{ Cohort $2(\mathrm{~N}=501)$} \\
\hline Prosocial skills & $4.13[4.08,4.18]$ & $4.13[4.06,4.19]$ & $4.07[3.99,4.15]$ & $4.09[4.01,4.17]$ \\
\hline Self-mastery & $3.57[3.51,3.62]$ & $3.50[3.43,3.58]$ & $3.43 * *[3.34,3.51]$ & $3.48[3.39,3.57]$ \\
\hline Social network & $3.60[3.52,3.67]$ & $3.51 *[3.42,3.59]$ & $3.43 * *[3.33,3.54]$ & $3.43 * *[3.33,3.54]$ \\
\hline Volunteering & $1.87[1.74,2.01]$ & $1.99[1.82,2.15]$ & $2.03[1.83,2.22]$ & $2.02[1.81,2.22]$ \\
\hline Organizing activities & $1.93[1.80,2.06]$ & $2.07[1.91,2.23]$ & $2.00[1.80,2.19]$ & $1.92[1.71,2.12]$ \\
\hline \multicolumn{5}{|l|}{ Cohort $3(\mathrm{~N}=639)$} \\
\hline Prosocial skills & $4.17[4.12,4.22]$ & $4.13[4.07,4.20]$ & $4.18[4.11,4.26]$ & $4.08 *[4.00,4.15]$ \\
\hline Self-mastery & $3.67[3.61,3.72]$ & $3.56^{* *}[3.49,3.62]$ & $3.49 * * *[3.42,3.57]$ & $3.48 * * *[3.41,3.56]$ \\
\hline Social network & $3.64[3.58,3.70]$ & $3.50 * *[3.43,3.58]$ & $3.53 *[3.44,3.62]$ & $3.49 * *[3.40,3.57]$ \\
\hline Volunteering & $2.21[2.07,2.34]$ & $2.48 * *[2.32,2.65]$ & $2.37[2.17,2.56]$ & $2.45 *[2.27,2.64]$ \\
\hline Organizing activities & $1.98[1.87,2.09]$ & $1.86[1.72,2.00]$ & $2.05[1.89,2.21]$ & $2.07[1.91,2.23]$ \\
\hline
\end{tabular}

Means and CI

$* * *$ Significant at $<0.001$; **significant at $<0.01$; *significant at $<0.05$; ns not significant

${ }^{a}$ Wave 1 is the reference category 
effect sizes in this type of provision should not be considered unimportant (Rose, 1993). After all, not all of the target population of youth work is at high risk of social and mental or other health problems.

This study did not observe significant improvements in the three cohort groups over the four time points (16 months) on prosocial skills, self-mastery, social network and organizing activities, although there was a cautious increasing trend in volunteering. Although the differences were small and were in most cases insignificant, they pointed in the same direction, suggesting a coherent underlying pattern of relationships between participation in youth work and doing volunteer work. We expected that Cohort 1 would show an increase in outcome variables at time point 4 after 16-22 months participation in youth work, reflecting the scores of Cohort 2 at time point 1 , as both groups would have participated in youth work for about the same time. Contrary to expectations, Cohort 1 showed no significant improvements over 16 months.

Reflecting on the method used, there are two possible explanations for this result. First, the sample scored at high levels on three of the five outcome variables at time point 1 , possibly diluting the effect of youth work. It could mean that a social desirability effect was possible, with the youngsters overestimating themselves, or that the youth work services studied were not successful in retaining those youngsters who were socially vulnerable. However, recent studies confirm that Dutch professional youth work does reach socially vulnerable youngsters, such as those with addictions, debt, social and/or mental health problems, or early school leavers (Meere \& Stoutjesdijk, 2019). Additionally, it is known that within the target group a division is made between youngsters who are doing well, youngsters with minor or initial problems, and youngsters with severe and multiple disadvantages (Sonneveld et al., 2020). Our finding that $33 \%$ of the young people gained access to additional support also suggests that youth work assists young people who request help with their personal or social problem(s). However, a further study with more focus on the extent of the personal and social problems of respondents has been suggested. Such a study may also reveal differences in effectiveness for the various sub-groups targeted by youth work.

Second, same-source bias (Podsakoff et al., 2012) might be present in this study, because the youngsters were asked to fill in the same questionnaire four times in a relatively short period of time. The respondents may have been unconsciously influenced by answers in previous measurements. Future longitudinal research might be conducted over a longer period and also use other informants to more precisely identify the different effects of youth work.

An interesting related question worthy of further investigation is why and how outcomes in youth work relate to personal and contextual factors, also known as "the black box" of youth work (Lundemark Andersen et al., 2020). Contextual factors may explain individual differences in development trajectories over time. We have sought more insight into the black box of youth work in a multiple case study (Sonneveld et al., 2020), in which we examined the differential effects of a multi-methodic approach on development of youngsters and the influence of important life events and significant others. In future work, we will explore in greater depth which methodic principles (Metz, 2016) (such as a meaningful relationship between youth and professional) are most valuable and related to outcome measures central to this study.

\section{Strengths and Limitations}

In addition to a greater understanding of the preventionfocused outcomes of a multi-methodic youth work approach, this study provides insight into how outcome evaluation is possible in the context of open-ended dynamic practice, the outcomes and effectiveness of which may be relatively difficult to assess. However, more investigation in this field is encouraged. One strength of the present study is its accelerated longitudinal design, which allowed us to track developmental shifts in a relatively efficient manner. Another strength is that we collaborated closely with 11 youth work organizations, which increased the extent to which our findings can be generalized. However, a number of limitations should be considered when interpreting the results of this study. The first concerns the sample, which only encompasses young people from urban areas. This explains the high percentage of respondents with a non-Dutch background. These results cannot be generalized to youth work in rural areas. Second, there is no comparison with a control group. In the context of professional youth work with an open approach, traditional techniques for measuring effectiveness, such as randomization (Wallander, 2012), are not suitable. In light of this, our study made a comparison of two cohorts with a reference group consisting of young people who had only participated in youth work settings for 0-6 months at baseline. As a consequence, there is not a fully adequate baseline measurement (i.e., youngsters' scores before taking part in youth work activities). Third, the sample size changed from measure to measure depending on the respondent and practical issues in the organizations involved. Due to the open-ended, flexible, and voluntary nature of this service, a substantial drop-out rate during the four waves was to be expected. Because of its voluntary nature, youngsters participate irregularly in youth work activities. Nevertheless, youth workers may identify the specific needs of young people and connect with these youngsters through an approach involving greater outreach (detached youth work). In this study, we attempted to register absences, but unfortunately it was not possible to 
observe the reasons for all non-completers. While we used the most appropriate analysis technique to handle missing data (Twisk, 2013), it may have affected the results. In future evaluation research in this type of setting, it is suggested that non-completers should be monitored more accurately to obtain a better profile of which youngsters drop out.

Finally, although Cronbach's alpha was satisfactory for all measurement scales, we are aware that the removal of some items from a validated scale can disrupt the reliability of the scale and the confidence of the output. Nevertheless, we chose scale adaptation to tailor the research to the specific research setting and to measure the overall preventive value of youth work among a broad age group.

\section{Implications for Practice and Policy}

This longitudinal study partially addresses the lack of academic literature on professional youth work. This study showed that professional youth work, as a low threshold collective service, fulfills a significant preventive role in social infrastructure and has the potential to reach youth who are at risk in one or more social contexts. The results provide valuable knowledge that supports the further professionalization and legitimation of professional youth work in social work practice, including the development of evidence-based practice. Youth workers can use the results to improve their support of socially vulnerable youngsters in their personal development and social participation. These findings are also very important for youth policy, which increasingly focuses on prevention and positive youth development. Based on these insights, it is recommended that further investment be directed at professional youth work. Despite the time required to achieve beneficial effects, youth work is a relatively accessible, low-cost service that could reach large numbers of socially vulnerable youngsters. More investment in youth work on a structural basis (rather than just short-term projects), in addition to existing social work practices for adolescents, may reduce costs and waiting lists for specialized social care institutions.

Acknowledgements This research was financially supported by the Netherlands Organization for Health Research and Development (ZonMw, Grant Number: 729200001) and Amsterdam University of Applied Sciences. The 11 youth work providers who participated in this research also supported the project by permitting their youth workers to devote time to cooperate in the research. We would like to express our special thanks and gratitude to Saïd Awad, Elif Cankor, Naomi Gaspersz and the managers, youth workers and youngsters who participated in this study.

\section{Declaration}

Conflict of interest The researchers and participating organizations declare that they have no conflict of interest.
Open Access This article is licensed under a Creative Commons Attribution 4.0 International License, which permits use, sharing, adaptation, distribution and reproduction in any medium or format, as long as you give appropriate credit to the original author(s) and the source, provide a link to the Creative Commons licence, and indicate if changes were made. The images or other third party material in this article are included in the article's Creative Commons licence, unless indicated otherwise in a credit line to the material. If material is not included in the article's Creative Commons licence and your intended use is not permitted by statutory regulation or exceeds the permitted use, you will need to obtain permission directly from the copyright holder. To view a copy of this licence, visit http://creativecommons.org/licenses/by/4.0/.

\section{References}

Abdallah, S. (2017). Struggles for success. Youth work rituals in Amsterdam and Beirut. Amsterdam: University of Amsterdam, Doctoral dissertation.

Asselt-Goverts, A. E. van. (2016). Social networks of people with mild intellectual disabilities: Characteristics and interventions (dissertation). Tilburg: Tilburg University.

Baillergeau, E. \& Hoijtink, M. (2010). Youth work and 'youth at risk' in the Netherlands: A review of literature. Sociétés et Jeunesses en Difficulté, Social Int (no. hors série).

Bartelink, C., \& Verheijden, E. (2015). Wat werkt bij het versterken van het sociale netwerk van gezinnen? Utrecht: Youth Institute.

Batsleer, J. R. (2008). Informal learning in youth work. London: SAGE.

Bergin, C., Talley, S., \& Hamer, L. (2003). Prosocial behaviours of young adolescents: A focus group study. Journal of Adolescence, 26(1), 13-32

Boomkens, C., Metz, J. W., Schalk, R. M. J. D., Regenmortel, V., \& Tine, M. R. F. (2019a). The role of social environment in acquiring agency in girls work. Children and Youth Services Review, 104, 104399. https://doi.org/10.1016/j.childyouth.2019.104399

Boomkens, C., Metz, J. W., Van Regenmortel, T. M., \& Schalk, R. M. (2019b). The development of agency in professional youth work with girls and young women in the Netherlands. Journal of Social Work, 19(6), 719-735. https://doi.org/10.1177/14680 17318784079

Bosscher, N. (2014). The decentralisation and transformation of the Dutch youth care system. Utrecht: Youth Institute.

Bradford, S. (2000). Disciplining PRACTICES: New ways of making youth workers accountable. International Journal of Adolescents and Youth, 9, 45-63

Catalano, R., Berglund, M., Ryan, J., Lonczak, H., \& Hawkins, D. (2004). Positive youth development in the United States: Research findings on evaluations of positive youth development programs. The Annals of the American Academy of Political and Social Science, 591, 98-124

Cavanaugh, A. M., \& Buehler, C. (2015). Adolescent loneliness and anxiety. The role of multiple sources of support. Journal of Social and Personal Relationships, 23, 149-170

CBS. (2020). Jeugdhulp 2019 [Youth care 2019]. The Hague: Statistics Netherlands (CBS).

Cohen, J. (1992). A power primer. Psychological Bulletin, 112, 155159. https://doi.org/10.1037/0033-2909.112.1.155

Conger, K., Williams, S., Little, W., Masyn, K., \& Shebloski, B. (2009). Development of mastery during adolescence: The role of family problem-solving. Journal of Health and Social Behavior, 50(1), 99-114

Coulston, K. (2010). Somewhere to talk, somewhere to listen. The role of youth clubs in supporting the mental health and emotional wellbeing of young people. London: Clubs for Young People. 
Cuijpers, P., Weitz, E., Cristea, I. A., \& Twisk, J. (2017). Pre-post effect sizes should be avoided in meta-analyses. Epidemiology and Psychiatric Sciences, 26(4), 364-368

De St. Croix, T. (2018). Youth work, performativity and the new youth impact agenda: Getting paid for numbers? Journal of Education Policy, 33(3), 414-438. https://doi.org/10.1080/ 02680939.2017.1372637

Dickson, K., Vigurs, C., \& Newman, M. (2013). Youth work: A systematic map of the research literature. Dublin: Department of Children and Youth Affairs.

Doherty, L. \& De St. Croix, T. (2019, Nov 18). The everyday and the remarkable: Valuing and evaluating youth work. Retrieved from: https://www.youthandpolicy.org/articles/valuing-andevaluating-youth-work/

Duncan, S. C., Duncan, T. E., \& Hops, H. (1996). Analysis of longitudinal data within accelerated longitudinal designs. Psychological Methods, 1(3), 236-248. https://doi.org/10.1037/1082989X.1.3.236

Dunne, A., Ulicna, D., Murphy, I., \& Golubeva, M. (2014). Working with young people: The value of youth work in the European Union. Brussels: IFC GHK.

Dworkin, J. B., Larson, R., \& Hansen, D. (2003). Adolescents' accounts of growth experiences in youth activities. Journal of Youth and Adolescence, 32(1), 17-26

Fish, M. (2014). The value of youth services towards child and adolescent mental health. Youth \& Policy, 12, 95-12

Fyfe, I., Biggs, H., Hunter, S., McAteer, J., \& Milne, D. (2018). The impact of community-based universal youth work in Scotland. A study commissioned by the Scottish Youth Work Research Steering Group. Edinburgh : YouthLink Scotland.

Galbraith, S., Bowden, J., \& Mander, A. (2017). Accelerated longitudinal designs: An overview of modelling, power, costs and handling missing data. Statistical Methods in Medical Research, 26(1), 374-398. https://doi.org/10.1177/0962280214547150

Gemmeke, M., Hilverdink, P., Hoogenes, A., Valkestijn, M., Vink, C., \& Smid, M. (2011). De emancipatie van het jongerenwerk [The emancipation of youth work]. Utrecht: Netherlands Youth Institute.

Heggestad, E., Scheaf, D., Banks, G., Hausfeld, M., Tonidandel, S., \& Williams, E. (2019). Scale adaptation in organizational science research: A review and best-practice recommendations. Journal of Management, 45(6), 2596-2627

Henderson, M., Scourfield, J., Cheung, S. Y., Sharland, E., \& Sloan, L. (2016). The effects of social service contact on teenagers in England. Research on Social Work Practice, 26(4), 386-398. https://doi.org/10.1177/1049731514557363

Ince, D., van Yperen, T., \& Valkestijn, M. (2018). Top ten positive youth development. Protective factors in parenting and growing up. Utrecht: Netherlands Youth Institute.

Jeffs, T., \& Smith, M. (1999). The problem of 'youth' for youth work. Youth and Policy, 62, 45-66

Kempen, G. (1992). Het meten van de gezondheidstoestand van ouderen; een toepassing van een Nederlandse versie van de MOS-schaal. TijdschriftvoorGerontologieen Geriatric, 23, 132-140

Koops, K., Metz, J., \& Sonneveld, J. (2013). We zijn de brug naar zelf aan de slag gaan. Onderzoeksrapport Ambulant Jongerenwerk in de grote stad. Amsterdam: Amsterdam University of Applied Sciences.

Koops, K., Metz, J., \& Sonneveld, J. (2014). Want zij gelooft in mij. Onderzoeksrapport Individuele Begeleiding in het jongerenwerk. Amsterdam: Amsterdam University of Applied Sciences.

Larson, R. W. (2011). Positive development in a disorderly world: SRA presidential address. Journal of Research on Adolescence, 21,317-334. https://doi.org/10.1111/j.1532-7795.2010.00707.x
Larson, R. W., McGovern, G., \& Orson, C. (2019). How adolescents develop self-motivation in complex learning environments: Processes and practices in afterschool programs. In A. Renninger \& S. Hidi (Eds.), Cambridge handbook of motivation and learning. (pp. 111-138). NYC: Cambridge Press.

Lundemark Andersen, M., Ingemann Brandt, L., Henriksen, K., Mejlvig, K., Nirmalarajan, L., Rømer, M., Uggerhøj, L., \& Wisti, P. (2020). Underlying theoretical positions, perceptions and foundations in practice research. In L. Joubert \& M. Webber (Eds.), The Routledge handbook of social work practice research. (pp. 57-67). Oxon/New York: Routledge.

Manders, W., \& Metz, J. (2017). Kern en meerwaarde van informatie \& advies in het jongerenwerk. Jeugdbeleid, 11(4), 263-270. https://doi.org/10.1007/s12451-017-0162-x

McGregor, C. (2015). Universal Youth Work. A critical review of the literature. Edinburgh: University of Edinburgh.

Meere, F. de., \& Stoutjesdijk, F. (2019). Náást de jongeren. De staat van professioneel jongerenwerk in Nederland. Utrecht: Verwey-JonkerInstituut.

Metz, J. (2016). The development of a method substantiated by research for girls' work. Journal of Social Intervention: Theory and Practice, 25(1), 47-70. https://doi.org/10.18352/jsi.431

Metz, J. (2017). The professionalism of youth work and the role of values. Social Work \& Society, 15(2), 1-16

Metz, J. (2020). The significance of youth work for prevention. A state of affairs. MensenMaatschappij, 95(2), 113-131. https:// doi.org/10.5117/MEM2020.2.003.METZ

Milburn, T., Forsyth, B., Stephen, S., \& Woodhouse, H. (2000). Thinking on your feet. Outreach and detached youth work with vulnerable young people. Edinburgh: Prince Trust.

Nolas, S. (2014). Exploring young people's and youth workers' experiences of spaces for 'youth development': Creating cultures of participation. Journal of Youth Studies, 17(1), 26-41. https:// doi.org/10.1080/13676261.2013.793789

Ord, J. (2014). Aristotle's phronesis and youth work: Beyond instrumentality. Youth and Policy, 112, 56-73

Ord, J., Carletti, M., Cooper, S., Dansac, C., Morciano, D., Siurala, L., \& Taru, M. (2018). The impact of youth work in Europe: A study of five European Countries. Helsinki: Juvenes Print.

Pearlin, L. I., Lieberman, M. A., Menaghan, E. G., \& Mullan, J. T. (1981). The stress process. Journal of Health and Social Behavior, 22, 337-356

Pearlin, L. I., \& Schooler, C. (1978). The structure of coping. Journal of Health and Social Behavior, 19(1), 2-21. https://doi.org/ $10.2307 / 2136319$

Podsakoff, P. M., MacKenzie, S. B., \& Podsakoff, N. P. (2012). Sources of method bias in social science research and recommendations on how to control it. Annual Review of Psychology, 63, 539-569

Rose, G. (1993). The strategy of preventive medicine. Oxford: Oxford University Press.

Rumping, S., Metz, J., Awad, S., Nijland, E., Manders, W., Todorovic, D., Sonneveld, J., \& Schaap, R. (2017). Groepswerk. OnderzoeknaarGroepswerkalsgeneriekemethodiek van het grootstedelijkjongerenwerk. Amsterdam: Amsterdam University of Applied Sciences.

Schaap, R., Todorovic, D., Awad, S., Manders, W., Sonneveld, J., \& Metz, J. (2017). Onderzoek naar Informatie \& Advies als specifieke methodiek van het grootstedelijk jongerenwerk. Amsterdam: Amsterdam University of Applied Sciences.

Sonneveld, J., \& Metz, J. (2019). De doelgroep van het jongerenwerk in cijfers. Wie maken gebruik van jongerenwerk en op welke manier? Amsterdam: Amsterdam University of Applied Sciences.

Sonneveld, J., Rijnders, J., Metz, J., Van Regenmortel, T., \& Schalk, R. (2020). The contribution of professional youth work to the 
development of socially vulnerable youngsters: A multiple case study. Children and Youth Services Review, 118, 105476. https://doi.org/10.1016/j.childyouth.2020.105476

Sonneveld, Metz, Schalk \& Van Regenmortel (under revision). Professional youth work as a preventive service: Toward an integrated conceptual framework.

Taru, M. (2010). Youth work in Tallinn: The positive impact on young people. Studies of Transition States and Societies, 2(2), $82-97$

Twisk, J. (2013). Applied longitudinal data analysis for epidemiology. Cambridge: Cambridge University Press.

Twisk, J., de Boer, M., de Vente, W., \& Heymans, M. (2013). Multiple imputation of missing values was not necessary before performing a longitudinal mixed-model analysis. Journal of Clinical Epidemiology, 66(9), 1022-1028. https://doi.org/10.1016/j.jclinepi. 2013.03.017

Vettenburg, N. (1998). Juvenile delinquency and the cultural characteristics of the family. International Journal of Adolescent Medicine and Health, 10(3), 193-210
VSNU. (2018). Netherlands code of conduct for Research Integrity. The Hague: Association of Universities in the Netherlands (VSNU). https://doi.org/10.17026/dans-2cj-nvwu

Wallander, L. (2012). Measuring social workers' judgements: Why and how to use the factorial survey approach in the study of professional judgements. Journal of Social Work, 12(4), 364-384

Widenfeld, B., Goedhart, A., Treffers, P., \& Goodman, R. (2003). Dutch version of the Strengths and Difficulties Questionnaire (SDQ). European Child \& Adolescent Psychiatry, 12, 281-289. https://doi.org/10.1007/s00787-003-0341-3

Zimmerman, M. A. (1995). Psychological empowerment: Issues and illustrations. American Journal of Community Psychology, 23(5), 581-599

Publisher's Note Springer Nature remains neutral with regard to jurisdictional claims in published maps and institutional affiliations. 